\title{
Preservação digital nas instituições de ensino superior: aspectos organizacionais, legais e técnicos
}

José Carlos Abbud Grácio

\begin{abstract}
Doutorado e Mestrado em Ciência da Informação pela Universidade Estadual Paulista Júlio de Mesquita Filho - UNESP/Marília. Graduação em Bacharelado em Ciência da Computação pela Universidade Estadual de Campinas - UNICAMP
\end{abstract}

Bárbara Fadel

Doutorado em História Social pela Universidade de São Paulo.Professor Assistente Doutor da Universidade Estadual Paulista Júlio de Mesquita Filho. Professor titular do Centro Universitário de Franca

Marta Lígia Pomim Valentim

Pós-Doutorado pela Universidad de Salamanca, Espanha. Livre Docente em Informação, Conhecimento e Inteligência Organizacional pela Unesp. Doutora em Ciências da Comunicação pela Escola de Comunicações e Artes da Universidade de São Paulo (ECA/USP)

Este artigo apresenta uma análise dos principais aspectos relacionados à preservação digital em Instituição de Ensino Superior (IES). Discute os problemas e os desafios a serem enfrentados nesse contexto e apresenta os principais aspectos e estratégias que envolvem a preservação digital nesse tipo de instituição, destacando três: os aspectos organizacionais, os aspectos legais e os aspectos técnicos. Os procedimentos metodológicos envolveram a análise da literatura da área sobre o tema. Como resultado, apresenta uma política de preservação digital que contempla 15 (quinze) elementos essenciais, distribuídos nos três segmentos (aspectos) e descreve a importância de cada um para a implantação de uma política de preservação digital.

Palavras-Chave: Preservação digital; Política de preservação digital; Gestão de documentos digitais; Gestão da informação; Tecnologias de informação e comunicação (TIC); Instituição de Ensino Superior (IES). 


\title{
Digital preservation in higher education institutions: organizational aspects, legal and technical
}

\begin{abstract}
This article analyzes the main aspects related to digital preservation in Higher Education Institution (HEI). Discusses the problems and challenges to be facing in this context and presents the main aspects and strategies involving digital preservation in this institution type, focusing on three: the organizational aspects, the legal aspects and the technical aspects. The methodological procedures involved the literature analysis on the subject area. As a result shows a digital preservation policy that includes 15 (fifteen) essential elements, distributed in three segments (aspects), and the importance of each element to the deployment of a digital preservation policy.
\end{abstract}

Keywords: Digital preservation; Digital preservation policy; Digital document management; Information Management. Information and Communication Technologies (ICT). Higher Education Institution (HEI).

Recebido em 14.10.2012 Aceito em 25.03.2013

\section{Introdução}

A sociedade contemporânea possui, como uma de suas características, o uso da informação e a constante mudança e evolução das Tecnologias de Informação e Comunicação (TIC). Nessa perspectiva, surge a necessidade de preservar um novo tipo de patrimônio - a informação digital - e, com ela, uma nova área de pesquisa, a preservação digital.

A informação digital tem contribuído para o desenvolvimento social e cultural, pois propicia, a diferentes comunidades, a possibilidade de acesso à informação e ao conhecimento, influenciando mudanças na cultura das organizações e dos indivíduos.

Nesse contexto, o indivíduo está inserido em um ambiente cada vez mais dependente de informação digital. No entanto, como toda nova tecnologia, apresenta problemas e desafios a serem enfrentados, dentre os quais se destacam: mudanças e avanços extremamente rápidos, no que tange às tecnologias de acesso à informação digital; capacidade de as pessoas e instituições assimilarem essas mudanças; obsolescência de hardware e software, que para Chapman (2001) é a nêmeses da preservação digital, ou seja, sua pior inimiga; explosão da quantidade de 
informação armazenada em meio digital; mudanças no formato dos arquivos e das mídias de armazenamento; e custo elevado das novas tecnologias.

Dessa forma, são necessários recursos humanos, hardware e software de armazenamento e de comunicação que trabalhem corretamente a informação digital e a coloquem à disposição das pessoas, para busca e recuperação, observando as mudanças decorrentes da obsolescência e dos avanços das TIC.

A Instituição de Ensino Superior (IES) que, por sua característica e objetivo possui grande quantidade de informação em formato digital, passa pelos mesmos problemas e desafios. O conhecimento produzido nesse tipo de instituição constitui-se em importante conjunto de informações que caracteriza o perfil acadêmico-científico de uma IES, bem como sua visibilidade em termos de país e de mundo.

Com base nas questões apresentadas, este artigo tem como objetivo contribuir com a área de Ciência da Informação, mais especificamente com os estudos sobre os aspectos relativos à preservação digital, de modo que possam subsidiar a elaboração de modelos de gestão voltados à preservação da informação digital em IES.

No contexto da IES, a preservação digital é uma necessidade premente, devido à explosão documentária em meio digital que ocorre nesse tipo de instituição, em razão principalmente do desenvolvimento das atividades de ensino (educação a distância), pesquisa (inovação) e extensão (responsabilidade social).

A pesquisa é descritiva e exploratória, cuja finalidade é proporcionar uma visão ampla sobre o tema preservação digital. Os procedimentos metodológicos utilizados baseiam-se no levantamento e revisão bibliográfica nas principais bases de dados acadêmicas nacionais e internacionais, sobre os principais temas relacionados à preservação digital e à gestão da informação em IES.

A partir da literatura selecionada, foram analisados conceitos e características da informação digital, identificados os principais aspectos que envolvem a preservação digital e como eles se relacionam no contexto da IES.

\section{Preservação digital}

Compreendemos preservação digital como um processo de gestão organizacional que abrange várias atividades necessárias para garantir que um objeto digital possa ser acessado, recuperado e utilizado no futuro, a partir das TIC existentes na época e com garantias de autenticidade. A autenticidade refere-se à garantia de que o objeto digital é autêntico, ou seja, que reflita o conteúdo original de sua criação/produção.

Pelas características da informação digital, a preservação digital envolve questões técnicas, culturais, legais, econômicas e administrativas e todas devem integrar a preservação física, lógica e intelectual dos 
objetos digitais e, portanto, devem estar inseridas em uma política de preservação digital das IES.

A preservação digital implica inicialmente em mudança dos elementos da cultura organizacional de uma IES, como valores, crenças, ritos, normas e comportamentos, exigindo das pessoas a consciência da importância da preservação. Essa percepção, por parte do indivíduo, somente é possível se houver princípios e valores que propiciem a valorização da preservação digital desde a sua produção. Para tanto, é necessário que a IES desenvolva uma cultura informacional positiva em relação à preservação digital.

Compreendemos cultura organizacional como um conjunto de princípios e valores que um determinado grupo considera válido e, portanto, o aceita, o compartilha, bem como passa a ser um norteador para perceber, pensar, sentir e agir em um determinado contexto (SCHEIN, 2001). A cultura informacional faz parte da cultura organizacional e abrange os princípios e valores voltados à informação e ao conhecimento.

Para se implementar uma política de preservação digital em uma IES é necessário o envolvimento de toda a comunidade e uma mudança da gestão institucional, ou seja, a instituição deve trabalhar uma cultura voltada à preservação digital, envolvendo valores, comportamentos e atitudes que incorporem a importância da preservação digital para o acesso e recuperação da informação e do conhecimento gerado no seu ambiente.

A cultura organizacional está relacionada à forma como as pessoas e os grupos interagem dentro da instituição, como elas repassam os princípios e valores organizacionais para os novos membros e como a instituição define as responsabilidades e tarefas para o sujeito organizacional no seu cotidiano (VALENTIM et al., 2003). Além da relação entre os indivíduos e o contexto interno da instituição, a cultura organizacional também é influenciada pelo ambiente externo, e no caso da preservação digital essa influência é acentuada devido a sua inserção no contexto das mudanças e dos avanços das TIC.

A cultura informacional, no âmbito da preservação digital, requer um comportamento e uma atitude, por parte dos indivíduos, que abrangem desde a produção até o descarte do objeto digital. Por isso, a cultura informacional também depende de normas organizacionais formais, que definam as responsabilidades e as tarefas relacionadas à preservação digital. Entre elas, citamos a importância de o produtor: a) incluir metadados na geração de um objeto digital; b) gerar um objeto digital em formato compatível com as TIC utilizadas na instituição; c) descrever de forma clara e concisa o conteúdo do objeto digital; d) informar possível validade do objeto digital; e) informar possível confidencialidade do objeto digital; entre outras (GRACIO; FADEL, 2011).

Assim, o produtor de objetos digitais, no âmbito de uma IES, tem responsabilidade sobre o processo de preservação. A cultura informacional influenciará, por meio de princípios e valores, que o produtor cumpra essa responsabilidade estabelecida nas normas organizacionais. 
Além disso, os valores, crenças e ritos se formam a partir da consolidação da cultura informacional, fato que possibilita aos novos indivíduos que chegam à IES adotarem a mesma forma de perceber, pensar e agir em relação à preservação digital.

Figura 1 - Dimensões da Preservação Digital

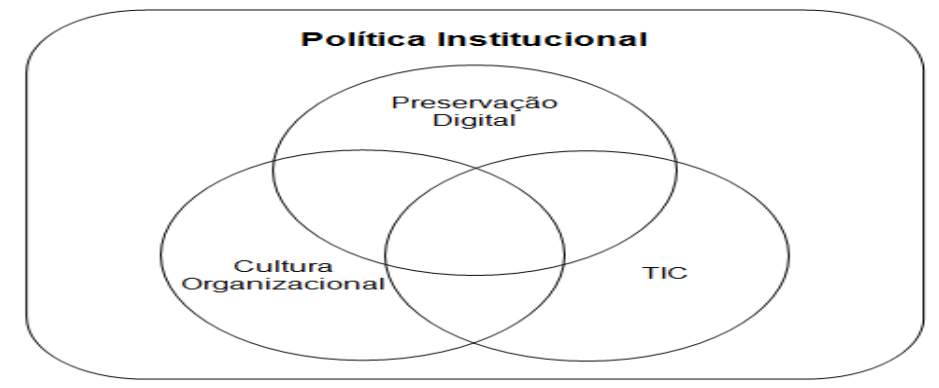

Fonte: Elaborada pelos autores.

A preservação digital está inserida em um contexto de inter-relação com as TIC e com a cultura organizacional, conforme representado na Figura 1, pois há a presença de problemáticas comuns às três áreas, assim como há a presença de certa complexidade, porquanto cada uma delas apresenta particularidades e questões próprias. As três áreas devem ser enfoque de uma política institucional voltada à preservação de objetos digitais.

Nessa perspectiva, propomos 15 (quinze) aspectos relativos à elaboração de uma política de preservação digital, divididos em três grupos: organizacional, legal e técnico, conforme apresentados na Figura 2. Apesar de possuírem suas próprias especificidades e características, esses grupos estão fortemente relacionados, da mesma forma que os aspectos que os compõem, assim como estão apoiados nas TIC e na cultura informacional, que formam o ambiente em que está inserida a preservação digital da instituição. Para a definição de um modelo de política e gestão da preservação digital, esses aspectos devem ser tratados conjuntamente. 
Figura 2 - Aspectos Relativos à Preservação Digital

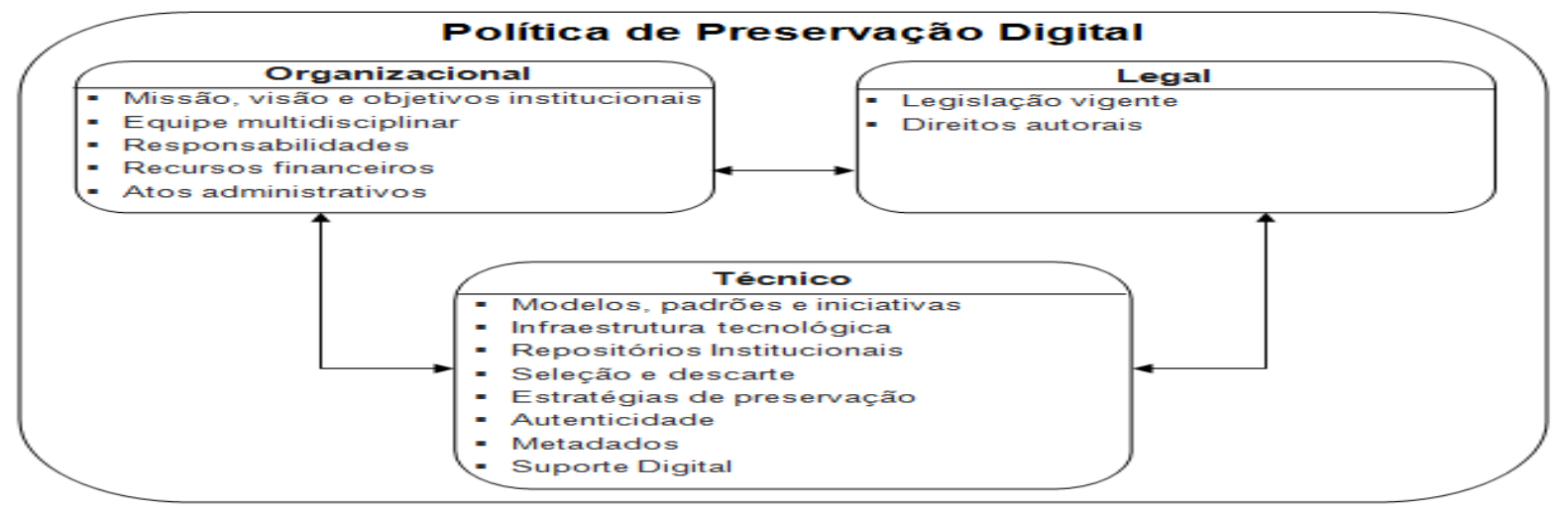

Fonte: Elaborado pelos autores.

\section{Preservação digital: aspectos organizacionais}

Os aspectos organizacionais da preservação digital dizem respeito à gestão e são relacionados à missão, visão e objetivos institucionais, a formação de uma equipe multidisciplinar especializada em atividades de preservação, o estabelecimento de responsabilidades, a definição de recursos financeiros para a sua manutenção. Esses aspectos buscam dar sustentação institucional à política, bem como propiciar estabilidade institucional para a continuidade das atividades de preservação digital no médio e longo prazo, independente das mudanças que possam ocorrer no nível estratégico da instituição. Os atos administrativos são essenciais para a sustentação e consolidação da política de preservação digital.

A implantação de uma política de preservação digital depende, inicialmente, da vontade da instituição, ou seja, deve estar inserida nos objetivos da IES e ir ao encontro da missão e visão institucional, pois são esses dois elementos que definem os objetivos institucionais. A questão da preservação digital está diretamente relacionada à visibilidade que a instituição deseja possuir junto à sociedade, bem como a posiciona em termos acadêmico e científico junto à sociedade produtora de conhecimento. As estratégias institucionais de médio e longo prazo, portanto, perpassam a questão da preservação digital, uma vez que esta influirá na imagem institucional, tanto no presente quanto no futuro.

Outro aspecto vinculado à missão, visão e objetivos institucionais é a definição dos tipos de informação existentes em meio digital que devem ser preservados. A definição deve ser realizada a partir do que a IES deseja em termos de visibilidade acadêmica, científica, tecnológica, artística e cultural. Nessa perspectiva, as políticas de preservação digital das IES sempre serão diferentes, apesar de possuírem elementos em comum.

Martins, Funari e Forti (2007, p. 5) ressaltam que, "[...] no momento, ainda não há políticas de preservação universais em aplicação obrigatória no Brasil", bem como que "[...] essas discussões não podem ser desvinculadas das reflexões internacionais". Nessa perspectiva, é necessária maior cooperação entre as IES, nacionais e internacionais, 
visando ao compartilhamento de experiências, ideias e problemas, de forma a minimizar esforços, diminuir custos, e possibilitar melhor interoperabilidade dos objetos digitais.

Uma política de preservação digital deve abranger distintos aspectos, conforme mencionado anteriormente. Para tratar de questões de naturezas tão distintas, não existe atualmente um profissional que possua formação tão ampla que contemple todos os aspectos que envolvem a preservação digital. Nesse sentido, surge a necessidade da IES formar uma equipe multidisciplinar, visando à gestão de fluxos, processos e responsabilidades no que tange a preservação digital. Existem várias formas de formalizar uma equipe multidisciplinar para este fim, uma delas é compor um comitê gestor, com funções e responsabilidades bem definidas.

Boeres e Arellano (2005) destacam a necessidade de as IES brasileiras definirem políticas de preservação digital, que incluam as necessidades de recursos humanos, tecnológicos e financeiros, além de outros aspectos relevantes, como os direitos autorais. Ressaltam, ainda, a falta de conhecimento e de pessoal especializado capacitado para atuar com a preservação digital.

O trabalho da equipe multidisciplinar deve ser voltado aos objetivos institucionais relacionados à preservação digital, sob os princípios da garantia de uma gestão adequada dos objetos digitais e com a finalidade de preservar a autenticidade e o acesso no longo prazo. A preservação digital está diretamente relacionada à necessidade de mudança na cultura organizacional/informacional, e as pessoas atuantes na IES têm um importante papel para que essa mudança ocorra. Nesse sentido, a equipe multidisciplinar deve estar preparada para lidar com esse aspecto relevante e essencial.

Geralmente a IES possui especialistas em suas instâncias, mas é imprescindível que esses especialistas atuem de forma integrada e em conjunto. A integração e o trabalho conjunto são fundamentais para a gestão organizada e estruturada dos fluxos, processos e responsabilidades.

Ressaltamos a importância de uma capacitação continuada desses profissionais, com o intuito de conhecer os aspectos relacionados à preservação digital e de atualizar os conhecimentos organizacionais, legais e técnicos, diante dos constantes avanços e mudanças que atingem a preservação digital.

A política de preservação digital deve contemplar - conjuntamente à definição da equipe multidisciplinar que comporá o comitê gestor para o gerenciamento dos objetos digitais produzidos na IES -, as responsabilidades afetam a cada um dos profissionais participantes.

A definição dos papéis e das responsabilidades dos profissionais que compõem a equipe é essencial, em função do volume de informações em formato digital produzido, da variedade de tipos informacionais, cujas características exigem tratamento e gestão diferenciados e, também, porque poderá haver conflitos e sobreposição de fluxos, processos e atividades. Dessa forma, o comitê gestor terá representantes de 
diferentes instâncias institucionais: administrativa, financeira, legal, informacional, tecnológica, entre outras.

Martins, Funari e Forti (2007, p. 20) afirmam que "[...] todo o conjunto administrativo, e também docente e discente, precisará ser sensibilizado para as questões digitais, de modo a que a capilaridade das ações atinja todos os membros da comunidade universitária".

A política de preservação digital deve definir claramente os deveres e as responsabilidades dos docentes e discentes para a preservação dos objetos digitais que produzem, neste caso, as informações acadêmicas, científicas e de extensão. Da mesma forma, no caso das informações administrativas, a política de preservação digital deve definir claramente os deveres e as responsabilidades do pessoal técnico-administrativo para a preservação dos seus objetos digitais.

A instância superior da IES deve responsabilizar-se pela definição dos objetivos a serem alcançados com a preservação digital, pela alocação de recursos permanentes no orçamento da instituição e pela formação da equipe multidisciplinar, que, por sua vez, elaborará e fará a gestão da política.

A preservação digital é uma atividade que requer a disponibilidade de recursos financeiros, pois envolve investimentos permanentes em infraestrutura, tecnologia e capacitação de pessoal. Esses recursos financeiros devem ser vistos como um investimento institucional para a preservação do capital intelectual da IES, ou seja, a produção acadêmica, científica, artística e cultural, bem como para a formação da memória institucional, por meio das informações administrativas, acadêmicas e científicas, uma vez que se constituem na história da instituição.

Os investimentos em TIC devem ser permanentes pela própria característica das tecnologias, ou seja, sua constante evolução e renovação continuada de hardwares, softwares, mídias, etc. Os custos de manutenção, de atualização e de inovação devem estar previstos no orçamento anual. Dessa forma, assegura que, mesmo quando ocorre mudança na instância superior da IES, os fluxos, processos e atividades de preservação permanecem como um dos objetivos institucionais.

O investimento anual para a preservação digital depende essencialmente do que a IES quer preservar no que tange aos objetos digitais produzidos em seu ambiente, bem como o nível e às condições de acesso e de recuperação que pretende oferecer a própria comunidade e a sociedade. Além disso, devem ser previsto recursos financeiros para a capacitação dos profissionais envolvidos e, neste caso, os custos dependerão das competências e habilidades que os profissionais já possuem, bem como das competências e habilidades que a IES necessita para cumprir os objetivos institucionais de preservação digital.

Uma política de preservação digital deve definir, para cada tipo de objeto digital, um conjunto de normas e procedimentos que assegurem a autenticidade, garanta os direitos do produtor (autor) e possibilitem o acesso ao seu conteúdo durante todo o ciclo de vida do objeto digital. A política deve ser registrada e aprovada pelas instâncias decisórias da IES 
e divulgada para toda a comunidade, objetivando dar ciência aos produtores e aos consumidores dos objetos digitais.

A definição de normas institucionais, que complementem a legislação vigente sobre preservação digital, é essencial, porque a legislação de modo geral é ampla e não atende a determinadas especificidades de uma IES, bem como é importante que a política institucional apresente resoluções, portarias e outros instrumentos normativos, que facilitem a compreensão e o desenvolvimento de processos e atividades vinculados à preservação digital, por parte de seus membros.

Dessa forma, a IES, através de atos administrativos, estabelece, de forma clara e sistematizada, as responsabilidades, direitos, deveres, métodos, técnicas, rotinas, entre outros, com o objetivo de orientar toda a comunidade no que tange a preservação digital e possibilita à administração da IES realizar sua função executiva. Os atos administrativos também auxiliam a formação e a consolidação da cultura organizacional/informacional voltada à preservação digital, uma vez que fomenta um determinado padrão de desempenho e conduta.

Ressaltamos que os atos administrativos estabelecidos pela IES não podem ser maior que a legislação vigente, uma vez que não seria constitucional. Assim, os atos estabelecidos para a preservação digital devem ser extraídos da legislação nacional e internacional, a fim de não comprometer a instituição com questões legais.

\section{Preservação digital: aspectos legais}

Primeiramente, referem-se às questões legais amplas, como a legislação nacional e internacional, que regem os direitos autorais e, em um segundo momento, refere-se às questões legais no âmbito institucional, cuja finalidade é garantir a legalidade dos fluxos, processos e atividades de preservação digital e garantir os direitos do produtor do objeto digital.

A política de preservação digital deve procurar seguir os padrões nacionais e internacionais, bem como a legislação vigente no país em que a IES atua. No Brasil não há legislação específica direcionada aos fluxos, processos e atividades relacionados à preservação digital. Contudo, há normatização para o documento arquivístico eletrônico, sendo que um dos itens contemplados é a preservação. Segundo essa normativa (CONSELHO NACIONAL DE ARQUIVOS - CONARQ, 2006), os documentos devem ser acessíveis e assegurar a autenticidade dos documentos digitais, a partir da adoção de ações institucionais e métodos e técnicas de preservação, por meio de uma política institucional de preservação digital.

Arellano e Andrade (2006, p. 9) apontam que "[...] a validade legal de documentos eletrônicos depende de sistemas que garantam a autenticidade e integridade das informações neles contidos, uma vez garantida, os legisladores deverão começar a regularizar esse aspecto". Observamos, portanto, a necessidade de leis nacionais específicas sobre preservação digital que propiciem legalidade aos fluxos, processos e 
atividades de preservação digital, bem como às instituições que querem atuar em um paradigma tecnológico mais contemporâneo, principalmente quando avaliamos as problemáticas advindas da armazenagem e da preservação de objetos em suportes não eletrônicos ou não digitais.

Evidenciamos que, mesmo não havendo legislação nacional específica para os aspectos que envolvem a preservação digital, é preciso que a IES conheça a legislação internacional vigente e as normativas específicas para esse fim, contando com um profissional da área jurídica na equipe multidisciplinar do comitê gestor.

Outro aspecto legal refere-se à questão do direito autoral, que atualmente pode ser considerado um dos ramos da Ciência Jurídica. Os direitos autorais se constituem em um dos segmentos da propriedade intelectual, cuja característica é a imaterialidade e, portanto, subjetiva, controvertida e polêmica.

A evolução das tecnologias de informação e comunicação traz consigo novas formas de relação de trabalho entre a instituição e os sujeitos que nela atuam, nesse contexto também surge a necessidade da evolução no que tange à proteção jurídica de obras intelectuais produzidas em formato digital (GANDELMAN, 2001).

Somente em 1973, o Brasil passou a contar com uma regulamentação específica do assunto, através da Lei no 5.988, de 14 de dezembro de 1973. Atualmente, a Lei no 9.160, de 19 de fevereiro de 1998, regulamenta os direitos autorais no país (BRASIL, 1998).

Como a preservação digital implica, muitas vezes, em reproduzir o objeto digital, o problema dos direitos autorais é um aspecto relevante. Evidenciamos que, se preservar implica em reproduzir ou copiar sem fins lucrativos, cuja finalidade é tornar o objeto digital disponível ao longo do tempo, a Lei no 9.610 não atende ao aspecto de preservação digital. Além de estar distante da realidade tecnológica atual, não trata de criar condições para os fluxos, processos e atividades de preservação digital, bem como no que se refere ao direito de acesso à informação, mais especificamente a produzida por IES pública, não atenta para a importância do registro do conhecimento produzido ser de acesso público.

Em relação à produção científica da IES, a preservação da propriedade intelectual é um aspecto relevante, pois implica em preservar a autoria original, garantindo a propriedade de produção (direito moral), assegurando a autenticidade do objeto digital e resguardando a instituição de problemas jurídicos futuros. Nessa perspectiva, ressaltamos que uma política de preservação digital deve estar amparada em leis que respaldem a instituição e garantam a propriedade intelectual ao autor do objeto digital, bem como sua autenticidade.

\section{Preservação digital: aspectos técnicos}

Refere-se às questões técnicas relacionadas aos fluxos, processos e atividades de preservação digital, envolvendo a infraestrutura tecnológica cujo enfoque é a obsolescência de hardware e software, do formato e suporte e das mudanças e avanços das TIC; os modelos, padrões e 
iniciativas de preservação digital, visando a um trabalho colaborativo entre IES; a seleção e descarte de objetos digitais; a autenticidade dos objetos digitais; os metadados que descrevem os objetos digitais, visando o acesso, busca e recuperação; as estratégias de preservação; o repositório institucional; e o suporte técnico institucional.

O uso de modelos de referência e de padrões internacionalmente aceitos é destacado pela literatura da área como uma importante ação de preservação digital, porquanto possibilita a troca de experiências e informações entre instituições, além de auxiliar na padronização de elementos que compõem a gestão de objetos digitais a serem preservados.

Arellano (2008) menciona que as iniciativas internacionais de preservação digital indicam a necessidade de utilização de padrões de metadados já estabelecidos e a utilização de documentos em formatos abertos, pois permitem a conversão para novos formatos, diante das mudanças constantes das TIC. Nesse sentido, uma das iniciativas para a definição de um formato aberto é conhecido como PDF/A, um formato para representação de documentos digitais, com o objetivo de preservar sua aparência visual ao longo do tempo, independente dos sistemas utilizados para sua criação, armazenamento ou leitura. Outro padrão aberto é o Open Document Format (ODF), um formato de arquivo para documento baseado em XML para aplicação em escritórios, e aprovado em 2006 pela Organization for the Advancement of Structured Infomation Standards (OASIS), pela International Organization for Standardization (ISO) e pela International Electrotechinal Commission (IEC) como um padrão internacional (ORGANIZATION..., 2006).

Um dos modelos mais recomendados atualmente é o Open Archival Information Systems (OAIS), desenvolvido pelo Consultative Committee for Space Data Systems (CCSDS). Este modelo está descrito pela norma ISO no 14721, de 2002, que apresenta o repositório digital, como sendo genérico, aberto a todas as comunidades e com garantias de confiabilidade.

Atualmente, o desafio da preservação digital é uma realidade enfrentada por diversas instituições, cujas iniciativas podem ser individuais ou colaborativas (entre instituições), tanto em nível nacional quanto internacional. De qualquer forma, os projetos são voltados ao estabelecimento de políticas de preservação digital, bem como à busca de soluções criativas, principalmente no que tange às informações relacionadas ao desenvolvimento científico e tecnológico. Os projetos colaborativos são interessantes, uma vez que propiciam a troca de experiências entre as instituições envolvidas, o compartilhamento de conhecimento entre os profissionais responsáveis pela preservação digital e a padronização de estratégias, modelos, técnicas e padrões que auxiliam na interoperabilidade dos objetos digitais. Por outro lado, os projetos colaborativos exigem tempo e esforço maiores, pois envolve demandas institucionais distintas, fator que pode gerar conflito durante a negociação e, às vezes, resultar em abandono de uma das partes. 
Como o desafio da preservação digital é global, a adoção de modelos, técnicas e padrões já testados e utilizados por instituições que trabalham com a preservação digital, garante maior eficiência e eficácia à política de preservação.

Como a preservação digital está diretamente relacionada às 'novas' TIC, qualquer política de preservação digital deve ser dinâmica e revista periodicamente, com o objetivo de acompanhar as constantes mudanças e avanços das TIC.

A infraestrutura tecnológica deve atender às distintas demandas de preservação digital e de disponibilização dos objetos digitais para a comunidade da IES, bem como para a sociedade. Dessa forma, deve atender dois ambientes tecnológicos: 1) infraestrutura de preservação, cujo objetivo é preservar os objetos digitais e seus respectivos metadados; e 2) infraestrutura de acesso, cujo objetivo é propiciar o acesso, a busca e a recuperação de objetos digitais com qualidade. Esses dois ambientes podem estar em infraestruturas tecnológicas distintas ou contidos na mesma infraestrutura, de forma integral ou parcial, dependendo da instituição e das soluções utilizadas.

A infraestrutura dos dois ambientes precisa dar sustentação principalmente para as seguintes demandas: de hardware e software; de armazenamento; de cópias de segurança; de redundância de banco de dados e de hardware; de detecção e recuperação automática de falhas; de acesso, busca e recuperação aos objetos digitais; e de estrutura de redes de computadores e de mecanismos de segurança.

Quanto ao aspecto humano, é preciso um programa permanente de capacitação do pessoal técnico responsável pela manutenção da infraestrutura, considerando a diversidade de atividades dos profissionais e as mudanças frequentes nas TIC, dado que a infraestrutura passa por constantes avanços e, consequentemente, pela necessidade de readequação às novas tecnologias.

Uma das formas de ampliar a divulgação da produção acadêmica, científica, técnica, artística e cultural de uma IES tem sido a utilização de modelos que permitem o livre acesso (Open Access) aos produtos de conhecimento gerados por seus membros. Esses modelos possibilitam aumentar a visibilidade institucional junto à sociedade de modo geral, bem como junto a sociedades científicas.

O repositório institucional, também denominado repositório digital, surge como um modelo para a divulgação e a comunicação da produção acadêmica, científica, técnica, artística e cultural, principalmente das IES públicas. Essa iniciativa tem sido realizada apoiada em estruturas tecnológicas que, utilizando a filosofia do acesso livre, permitem a publicação e a disseminação do conhecimento gerado em uma IES. O repositório proporciona uma forma rápida e ágil de divulgação dos resultados das pesquisas, a um custo menor e para um maior número de pessoas e instituições.

Da mesma forma que a preservação digital exige investimentos de longo prazo, os repositórios institucionais também necessitam de planejamento e investimentos em infraestrutura continuamente, pois 
utilizam tecnologias para armazenamento, acesso, busca e recuperação da informação que precisam ser atualizadas e preservadas. Arellano (2008) sugere a utilização dos softwares EPrints e DSPACE para a implantação de repositórios institucionais, porquanto ambos propiciam o armazenamento, acesso, busca e recuperação de informações em formato digital, e utilizam metadados para a descrição dos objetos digitais.

Dessa forma, os repositórios institucionais devem ser sustentáveis, ou seja, capazes de gerenciar e manter os dados disponíveis ao longo do tempo. Ressaltamos também que uma IES pode ter mais de um repositório institucional, isso dependerá essencialmente dos objetivos institucionais.

No ambiente digital atual, o volume de informação digital produzido em uma IES é significativo e cresce na proporção da necessidade de se gerar novos conhecimentos e inovação. Nesse sentido, é impossível gerenciar, armazenar e preservar toda a informação digital produzida nesse tipo de instituição, portanto, é preciso selecionar as informações relevantes que devem ser preservadas. Assim, surge um aspecto importante da preservação digital: a seleção.

A política de preservação digital deve elaborar diretrizes que contemplem os aspectos relacionados à seleção de objetos digitais, o que implica em definir quais são os objetos digitais relevantes para a instituição preservar. Para tanto, a política de preservação digital deve se basear nos objetivos institucionais e nas necessidades da comunidade interna e da sociedade, conforme explicam Boeres e Arellano (2005, p. 7), a seleção é um dos aspectos primordiais da preservação digital, pois "[...] é impraticável e ineficaz preservar tudo, para todos, para sempre".

Evidenciamos, também, que a seleção do que deve ser preservado em uma instituição perpassa a questão dos 'custos da preservação' e dos 'benefícios da preservação', ou seja, é necessário avaliar o melhor para a instituição em termos de custo/benefício. Dessa forma, os critérios devem ter como premissa atender às necessidades institucionais, os produtores dos objetos digitais e os usuários dessas informações, através de o estabelecimento da melhor relação entre o que deve ser preservado e os custos para o desenvolvimento dessa atividade.

É necessário definir, também, as prioridades referentes ao cronograma de preservação dos objetos digitais selecionados, pois as atividades de preservação digital podem sofrer atrasos ou restrições devido ao grande volume de informações.

Desse modo, a política de preservação digital deve prever, em suas diretrizes voltadas à seleção, a necessidade de revisão periódica dos critérios que definem o que é objeto digital prioritário, uma vez que a tomada de decisão é realizada em cima de premissas, como atender aos objetivos e necessidades institucionais, aos produtores dos objetos digitais e aos usuários dessas informações, e essas premissas podem ser modificadas ou ajustadas pela instituição, exigindo, assim, uma reavaliação da decisão.

Tão importante quanto a seleção, o descarte de objetos digitais também exige que a política de preservação estabeleça diretrizes que 
definam claramente, quais são os objetos digitais que podem ou devem ser descartados. O objetivo dessas diretrizes - baseadas na legislação vigente e nos atos administrativos -, é estabelecer responsabilidades, prazos, formas, entre outros. Para tanto, pode-se aplicar instrumentos como a Tabela de Temporalidade, entre outros.

Ressaltamos que a política de preservação, mais especificamente no que tange ao descarte de objetos digitais deve ser atualizada constantemente, uma vez que há alteração da legislação, bem como dos atos normativos internos, portanto, há a necessidade de atualização não só das diretrizes voltadas ao descarte, mas, também, dos instrumentos elaborados para tal atividade.

É necessário que a IES adote estratégias de preservação digital para cada tipo de objeto digital sob sua responsabilidade, avaliando periodicamente as tecnologias existentes e, assim, atualizar e ajustar as estratégias de preservação.

Um dos requisitos é que a equipe técnica responsável pelas estratégias de preservação esteja atenta e avalie as mudanças que estão ocorrendo no ambiente digital, prevendo a obsolescência de tecnologias que estão sendo usadas, bem como conhecendo e se capacitando em tecnologias emergentes.

Em relação às estratégias de preservação, podem ser definidos dois tipos de conservação: 1) conservação do objeto digital no seu formato original, que permite preservar o objeto digital na sua forma original, sem alterar sua estrutura, tais como o refrescamento (consiste em transferir a informação digital de um suporte físico de armazenamento para outro mais atual) e a emulação (utilização de um software, designado emulador, capaz de reproduzir o comportamento de uma plataforma de hardware e/ou software); e 2) conservação do conteúdo intelectual do objeto digital, que consiste na técnica de transferir periodicamente um objeto digital de uma tecnologia de hardware e/ou software para outra mais atual, como a migração (FERREIRA, 2006). Destacamos que, ao longo da vida do objeto digital, é possível utilizar distintas estratégias de preservação, dependendo do contexto tecnológico ao qual o objeto foi tratado inicialmente.

É consenso a necessidade do desenvolvimento de elementos de descrição, com o propósito de descrever o histórico das estratégias de preservação aplicadas aos objetos digitais, de forma que esse objeto possa ser entendido no futuro pelos novos ambientes tecnológicos. Assim, a aplicação de metadados especificamente vinculados à preservação é indicada como uma atividade essencial.

O ambiente digital, por suas características tecnológicas, possibilita a realização de alterações no objeto produzido originalmente. Desse modo, ao mesmo tempo em que hardware e software facilitam o desenvolvimento de atividades e tarefas, torna-se um fator de risco quando se trata da autenticidade do objeto digital.

Nesse contexto, as propriedades relacionadas ao suporte do objeto digital não garantem sua autenticidade, uma vez que o suporte em si não é garantia para que a informação permaneça autêntica durante todo o 
ciclo de vida, pois preservar normalmente significa mudanças de formato, de suporte (mídia) de armazenamento e, até mesmo, de estrutura de armazenamento e apresentação do objeto digital.

É necessário que a equipe responsável pelas atividades de preservação digital aplique métodos, técnicas e rotinas adequados que garantam a autenticidade do objeto digital. A equipe deve, a partir de informações e conhecimentos, prospectar, analisar e selecionar tecnologias adequadas para essa atividade, e após sua aplicação deve registrar todos os procedimentos executados, retroalimentado os fluxos e rotinas inerentes a autenticidade digital.

Uma das propriedades importantes para garantir a autenticidade de objetos digitais é a utilização de metadados. A literatura sobre essa temática ressalta que os metadados são considerados um dos requisitos essenciais para garantir a autenticidade de um objeto digital.

Apesar de a autenticidade também estar relacionada às questões organizacionais, como os objetivos institucionais, definimos a autenticidade como um aspecto técnico devido à sua forte relação com os metadados.

Além disso, é necessário que a IES, por meio da política de preservação digital e dos atos normativos internos, defina o que é autenticidade de um objeto digital e como o produtor desse objeto deve proceder em relação a alterações e atualizações. A instituição deve basear-se em leis nacionais e internacionais, garantindo a autenticidade dos objetos digitais, padronizando as atividades que visam à autenticidade, garantindo que os fluxos, processos e atividades sejam compatíveis com a prática do país e do exterior.

As mudanças que ocorrem frequentemente nas TIC, principalmente nos suportes e nos formatos de armazenamento, requerem a aplicação de estratégias de preservação ao longo do tempo. Os metadados relacionados à preservação digital devem acompanhar o ciclo de vida do objeto digital, desde a produção original até a última estratégia de preservação, registrando cada estratégia aplicada e as mudanças ocorridas com o objeto digital.

Metadados pode ser definido como um "[...] conjunto de elementos que descrevem as informações contidas em um recurso, com o objetivo de possibilitar sua busca e recuperação" (GRÁCIO, 2002, p. 23). O conjunto de elementos representa o conteúdo do objeto digital, ou seja, a descrição contém informações que possibilitam a identificação do conteúdo de um determinado objeto digital. Esses elementos devem, preferencialmente, seguir esquemas de codificação, como o uso de vocabulário controlado, esquemas de classificação e formatos de descrição formais, com o objetivo de proporcionar melhor qualidade de descrição.

Os metadados podem ser divididos em: metadados descritivos relativos ao conteúdo do objeto digital; e metadados descritivos relativos a informações administrativas e técnicas que permitam o registro das decisões tomadas no que tange as ações e estratégias de preservação, assegurando sua autenticidade. Para Sayão (2010, p. 10), os metadados de preservação são definidos "[...] de uma forma simples e direta, como a 
informação que apoia e documenta a preservação de longo prazo de materiais digitais" e devem se adequar às necessidades de registro dos processos de gestão relacionados à preservação digital. Dessa forma, os metadados de preservação expressam todas as estratégias de preservação aplicadas ao objeto digital desde sua criação, bem como as informações necessárias para sua representação pelas TIC atuais.

Existem muitos padrões de metadados, sendo que cada qual é aplicado a determinado tipo de informação. Entre os metadados aplicados a informações disponíveis em IES, destacam-se o Dublin Core (DC), mais simples e genérico e, justamente por isso, é amplamente utilizado, e o Metadata Encoding and Transmission Standards (METS), mais complexo e sofisticado.

Dessa forma, a definição dos metadados de preservação deve ser criteriosa e respaldada em padrões internacionalmente aceitos, que atendam ao interesse da IES, no que tange à preservação de objetos digitais sob sua custódia.

O suporte digital é outro aspecto importante para a preservação digital e pode ser definido como um dispositivo de armazenamento ou o meio físico no qual a informação digital está armazenada, independente de seu formato. Os principais fatores que levam à necessidade de transferência periódica de um suporte para outro são: a) deteriorização do suporte; b) obsolescência do suporte e de suas ferramentas de acesso (hardware e software); e c) desejo da instituição em buscar dispositivos mais modernos.

A deteriorização do suporte, também chamada de degradação, pode ser causada por problemas na mídia de armazenamento ou por fatores externos, e "[...] pode ser invisível e catastrófica o que coloca em risco o acervo digital" (INNARELLI, 2006, p. 136).

A expectativa de vida útil dos suportes digitais varia de acordo com o tipo de suporte, bem como com o ambiente no qual os objetos estão armazenados. Portanto, a IES deve realizar auditorias periódicas para verificação de sua integridade, principalmente no ambiente tecnológico de preservação. Os fatores externos estão relacionados ao ambiente no qual o suporte está sendo preservado, e as principais variáveis são: a) umidade do ar; b) temperatura; c) poluentes ambientais; e d) ação inadequada das pessoas responsáveis em preservar o suporte.

A obsolescência do suporte está diretamente relacionada à obsolescência do hardware e do software necessários para o acesso, leitura e interpretação dos bits armazenados. A IES também pode realizar a transferência de objetos digitais de um suporte para outro por questões próprias, como a mudança de um sistema de informação ou dos mecanismos de acesso aos objetos digitais, bem como por adquirir suporte com tecnologia mais avançada.

No contexto atual, em que as pessoas buscam, com maior frequência, informações disponíveis na Internet, os suportes para infraestrutura de acesso devem prover alta capacidade de armazenamento, de acesso, de busca e de recuperação, possibilitando o acesso aos objetos digitais com eficiência. 


\section{Considerações finais}

A preservação digital está relacionada à cultura organizacional e às tecnologias de informação e comunicação. Assim, sua implantação envolve mudanças nas atividades, na rotina, no comportamento, nos valores institucionais e na forma com que as pessoas e os grupos lidam com as TIC. Essas pessoas devem ser treinadas para as atividades relacionadas à preservação digital, com atenção ao conteúdo, ao suporte e ao uso dos objetos digitais.

A preservação digital deve estar inserida nos objetivos institucionais, a partir da formulação de uma política de preservação digital, que contemple aspectos organizacionais, legais e técnicos.

Esse tipo de política é essencial para as instituições de ensino superior, principalmente as públicas, que possuem, como característica natural, as mudanças periódicas de gestores do nível estratégico e, portanto, sofrem alterações em relação aos objetivos, metas, estratégias de ação e prioridades.

Uma política de preservação digital deve abranger os 15 (quinze) aspectos apresentados, com diretrizes, critérios e objetivos préestabelecidos e com normas e procedimentos que sejam amplamente disseminados à comunidade da IES.

A participação do produtor do objeto digital é essencial, assim, a IES deve desenvolver uma cultura que valorize os procedimentos de preservação digital. Além disso, as demandas e as necessidades de acesso, de busca e de recuperação determinam juntamente com as TIC o modelo a ser adotado pela IES, bem como de que forma cada tipo de objeto digital deve ser preservado.

A preservação digital, por envolver diferentes aspectos e distintas competências, necessita do envolvimento de profissionais de várias áreas da IES, que, por sua vez, devem ser comprometidos com o trabalho em equipe e com os objetivos institucionais.

Como a assimilação de uma cultura de preservação digital, por parte dos membros de uma determinada instituição, perpassa o conhecimento de algumas questões organizacionais, legais e técnicas, a IES deve implantar a partir da política de preservação digital, programas que promovam a preservação digital, bem como propicie ampla capacitação de seus membros, através de palestras, cursos, reuniões, entre outras ações.

Os desafios são inúmeros e de distintas naturezas. Nessa perspectiva, a demora em estabelecer uma política de preservação digital, bem como a implantação de programas e projetos específicos de preservação digital, põe em risco a integridade, a autenticidade, o acesso, a busca e a recuperação de objetos digitais importantes para a IES, com a possibilidade de perdas irreversíveis.

\section{Referências}

ARELLANO, M. A. Critérios para a preservação digital da informação científica. Brasília: UnB, 2008. 354f. Tese (Doutorado) - Programa de Pós- 
Graduação em Ciência da Informação, Universidade de Brasília, Brasília, DF, 2008.

ARELLANO, M. A.; ANDRADE, R. S. Preservação digital e os profissionais da informação. DataGramaZero: Revista de Ciência da Informação, Rio de Janeiro, v.7, n.5, 2006. Disponível em: <http://www.dgz.org.br/out06/Art_05.htm>. Acesso em: 29 abr. 2008.

BOERES, S. A. A.; ARELlANO, M. A. M. Políticas e estratégias de preservação digitais de documentos. In: ENCONTRO DE CIÊNCIA DA INFORMAÇÃO - CINFORM, 6., 2005, Salvador. Anais eletrônicos... Salvador: UFBA, 2005. Disponível em: <http://www.cinformanteriores.ufba.br/vi_anais/docs/SoniaMiguelPreservacaoDigital.pdf>.

Acesso em: 22 ago. 2013.

BRASIL. Lei 9.610, de 19 de fevereiro de 1998. Altera, atualiza e consolida a legislação sobre direitos autorais e dá outras providências. Brasília, DF, $1998 . \quad$ Disponível em: <http://www.planalto.gov.br/ccivil_03/LEIS/L9610.htm>. Acesso em: 3 set. 2009.

CHAPMAN, S. What is digital preservation? In: DIGITAL PRESERVATION RESOURCES SYMPOSIUM, 2001, Dublin, OH. Presentations... Disponível em:

<http://www.oclc.org/news/events/presentations/2001/preservation/chap man.htm>. Acesso em: 13 maio 2010.

CONSELHO NACIONAL DE ARQUIVOS (CONARQ). Modelo de requisitos para sistemas informatizados de gestão arquivística de documentos (eARQ Brasil). Brasília, 2006. 133p.

FERREIRA, M. Introdução à preservação digital: conceitos, estratégias e actuais consensos. Guimarães, Portugal: Escola de Engenharia da Universidade do Minho, 2006.2 Disponível em: <https://repositorium.sdum.uminho.pt/bitstream/1822/5820/1 /livro.pdf>. Acesso em: 17 jan. 2007.

GANDELMAN, H. De Gutenberg à internet: direitos autorais na área digital. 4. ed. Rio de Janeiro: Record, 2001. 333p.

GRÁCIO, J. C. A. Metadados para a descrição de recursos da Internet: o padrão Dublin Core, aplicações e a questão da interoperabilidade. Marília: Unesp, 2002. 104f. Dissertação (Mestrado) - Programa de Pós-Graduação em Ciência da Informação, Faculdade de Filosofia e Ciências, Universidade Estadual Paulista, Marília, 2002.

GRÁCIO, J. C. A. Preservação digital na gestão da informação: um modelo processual para as instituições de ensino superior. Marília: Unesp, 2011. 223f. Tese (Doutorado) - Programa de Pós-Graduação em Ciência da Informação, Faculdade de Filosofia e Ciências, Universidade Estadual Paulista, Marília. 2011. 
GRACIO, J. C. A; FADEL, B. Atuação do profissional da informação no conjunto de aspectos relacionados à preservação digital. Revista EDICIC, v. 1, n. 3, p. 301-318, Jul./Sep. 2011. Disponível em: <http://www.edicic.org/revista/index.php?journal=RevistaEDICIC\&page $=$ article\&op=view\&path\%5B\%5D=67> . Acesso em: 15 jan. 2012.

INNARELLI, H. C. Preservação de documentos digitais: confiabilidade de mídias CD-ROM e CD-R. Campinas: UNICAMP, 2006. 170f. Dissertação (Mestrado) - Universidade Estadual de Campinas, Faculdade de Engenharia Mecânica, Campinas, 2006.

MARTINS, N. R.; FUNARI, P. A.; FORTI, M. A. A gestão arquivística de documentos digitais: relato de experiências. 2007. Disponível em: <http://www.asocarchi.cl/DOCS/102.pdf>. Acesso em: 14 ago. 2009.

ORGANIZATION FOR THE ADVANCEMENT OF STRUCTURED INFORMATION STANDARDS (OASIS). Open by sesign: the advantages of the OpenDocument Format (ODF). 2006. Disponível em: <http://www.oasisopen.org/committees/download.php/21450/oasis_odf_advantages_10dec 2006.pdf>. Acesso em: 29 dez. 2010.

SAYÃO, L. F. Uma outra face dos metadados: informações para a gestão da preservação digital. Encontros Bibli: Revista Eletrônica de Biblioteconomia e Ciência da Informação, Florianópolis, v. 15, n. 30, p. 131, 2010.2 Disponível em: <http://www.periodicos.ufsc.br/index.php/eb/article/view/12528/14379>. Acesso em: 10 jan. 2011.

SCHEIN, E. H. Guia de sobrevivência da cultura corporativa. Rio de Janeiro: José Olympio, 2001. 192p.

THOMAZ, K. P. Gestão e preservação de documentos eletrônicos de arquivo: revisão de literatura - parte 2 . Arquivística.net, Rio de Janeiro, v. 2, n. 1, p. 114-131, 2006. Disponível em: <http://www.arquivistica.net/ojs/include/getdoc.php?id=194\&mode=pdf > . Acesso em: 15 jul. 2009.

VALENTIM, M. L. P. et al. O processo de inteligência competitiva em organizações. DataGramaZero: Revista de Ciência da Informação, Rio de Janeiro, v. 4, n. 3, 2003. Disponível em: <http://www.dgz.org.br/jun03/Art_03.htm>. Acesso em: 10 jan. 2010. 